\title{
Applications of Modern Information Technology in the Teaching of College Curriculums
}

\author{
WENYA XIAO, JIANXIA GE \\ Center of Modern Education Technology \\ Xinxiang Medical University \\ Xinxiang, China \\ 403447906@qq.com
}

\begin{abstract}
In this paper, it carries out more in-depth study on the integration of modern educational technology with college curriculums, especially on the application of multimedia technologies in the college teaching and obtains some valuable achievements. There are many issues worthy of study on the integration of modern information technology with college curriculums; in this paper it carries out certain researches from multimedia technologies on issues of teaching resources in college curriculums and classrooms, issues of courseware in the production and use processes, and issues of the integration of the traditional teaching method and modern teaching methods, etc., aspects, in which direction many problems are waiting for us to study, explore and solve.
\end{abstract}

Keywords-information technology, college, teaching, curriculums

\section{INTRODUCTION}

It has distinct characteristics of the times in 21 century: with the accelerated arrival of the knowledge economy and the rapid development of science and technology, international competitions have become increasingly fierce. In the era of knowledge economy characterized by innovations and applications of knowledge, training innovative talents has become the key of the impacts on the survival and development of the entire nation. The era of knowledge economy calls for the higher education to train more talents with innovative spirits and innovative abilities to meet the demand for talents, while modern information technology provides a platform to cultivate innovative talents, for which the effective approach is to accelerate the integrating pace of information technology with subject curriculums, hence, it must accelerate the integrating pace of information technologies with subject teachings.

Modern information technology has been widely applied to higher education; many teachers use multimedia, CAI courseware and other modern educational technology in their teaching; from the available materials point of view, educators and practitioners have relatively lacked researches on the issue of multimedia used in the college teaching so far, thus the related research results are less. Research conclusions mostly are obtained from the teaching experience or questionnaire surveys, and researches are conducted in constructions of hardware and software, or in reforms on modern education and teaching, etc. single aspects; from the referred materials point of view, no one has ever conducted systematic study on the multimedia teaching process from two dimensions of teachers and students, the education, the psychology, etc. different angles, meanwhile it lacks in-depth study on the negative effects of multimedia on teachers' classroom teachings and on the restraining factors of multimedia in the aspect of software developments.

This study focuses to start from the use of multimedia in the college classroom teaching to discuss the respective strengths of traditional teaching methods and multimedia teaching methods and their relationships, emphasizes to analyze the nature of the existing problems for the multimedia teaching in the integration with curriculum teaching, and analyzes what are the factors affecting the multimedia teaching effects? These problems to some extent directly or indirectly restrict the integration of modern educational technology with teaching, and will also have some negative impacts on modern educational reforms. If these problems can be well resolved, it will be of certain reference value for the reforms in the college teaching and curriculums, meanwhile it will plays both guidance and reference roles in college teachers' better uses of multimedia for teaching, optimizations of teaching processes, improvements of teaching quality, and realizations of optimal teaching.

\section{THE NECESSITY AND SIGNIFICANCE OF COLLEGE} TEACHING TO APPLY MODERN INFORMATION TECHNOLOGY

"Information Technology" is one of the most frequently used words in today's information society. Due to its different purposes, scopes, and levels of use, it has been provided with many different interpretations. Mr. Guonong Nan, a famous expert on educational technology in China, holds that Information Technology refers to a system performing collections, processing, storages, communications, and applied means and methods for information. Its connotations consist of two aspects: one is means, a variety of information media, as a materialized form of technology; the other one is methods, using information media to carry out collections, processing, storages, communications, and applied methods for various information, as an intelligent form of technology. Information Technology is composed of two elements of information media and applied methods of information media. The applied modern information technology in 
education and teaching is called Modern Educational Media. Modern educational media include visual media (slides and projectors), audio media (recordings, radios, and CD players, etc.), audio-visual media (slides /recordings, films, televisions, camera systems, VCD players, and DVD players, etc.), integrated media (computer teaching system, language laboratory system, multimedia combination teaching system, computer-aided instructional system, and computer network teaching system, etc.).

Multimedia with computer-assisted instruction (CAI) carries out educational activities taking a computer as the main media, that is using a computer to assist teachers to perform teaching functions and activities. It uses graphics, animation, sounds, and images, etc. various media to present and deliver course contents, which represents a broad field of computer applications, and also represents a new educational technology. From the educational communication point of view, CAI is a teaching form taking a computer as an educational media that teachers (educators) perform teaching through the interactions of students (educated objects) with computers. Multimedia with computer-assisted instruction can be divided into two main modes of the classroom teaching mode and the network interactive mode according to different roles and tasks of teachers, students and the computer in the teaching process, hereafter taking the application of the classroom teaching mode as the object of the study.

During the classroom teaching in the form of class teaching, according to demands of teaching contents and teaching objectives, it inherits advantages of the traditional teaching media, reasonably and appropriately introduces modern teaching media, and moderately plays their strengths in proper quantities, complementing one another and developing their own strengths, to form an optimal teaching media group of teaching information transmissions and feedback regulations, and participating in the whole process of the classroom teaching so as to achieve the optimization of the teaching process.

The so-called integration of information technology with subject curriculums is to create an ideal teaching environment through the effective integration of information technology into the teaching processes of each subject, so as to achieve a new way of learning that can fully reflect the subject status of students characterized by "independence, exploration and cooperation". It can be seen that the integration of information technology with curriculums not only uses information technology as a tool to assist teaching or learning, but stresses that it needs to use information technology to create an ideal teaching environment, in order to achieve a new learning method that can support requirements of self-explorations, multiple interactions, scene creations, cooperative learning, resource sharing, and many other aspects, consequently fully mobilizing students' initiatives and enthusiasms, so that the structure of the classroom teaching has fundamental changes, making students' innovative spirit and practical ability get implemented. This is the request of the key target for the quality education (i.e. training innovative talents).
With the advance of educational modernizations, the traditional education has been gradually integrated with modern new ideas, new tools, and new methods, embarking on a development road of modern education. How to move the traditional teaching towards modernizations, how to integrate the traditional teaching thoughts with modern teaching thoughts, how to change the traditional teaching to adapt to the development of modern teaching, and how to integrate the traditional teaching means with modern teaching means all are issues worthy of further considerations and discussions. There main ways for the traditional teaching to change towards modern teaching, one of which is to refer modern teaching theories and thoughts to structure a new teaching model and instructional design, and the other of which is to rationally and actively apply modern educational media to reform classroom teaching and improve the efficiency of classroom teaching, which is to realize the integration of modern information technology with subject teaching.

\section{ROLES OF MULTIMEDIA AND OTHER MODERN} INFORMATION TECHNOLOGIES IN COLLEGE TEACHING

\section{A. Teachings Are Free from Constraints of Time, Space and Geography}

Modern educational technologies can make teachings free from constraints of time, space and geography, which can reproduce historical pictures and scenes in different places in front of students. For example, in the teaching of geological profession, when explain the typical geological sections across the country, students in school are impossible to arrive at these places, whereas when produce all the typical sections into a TV teaching film, students can "travel" around the country without coming out of school and have a macro understanding of various typical sections, so that students will broaden their fields of vision and also increase their knowledge.

\section{B. Able to Visualize the Abstract Contents}

There are some abstract contents in each college course. For example, when teachers explain the calculus calculations of some physical problems, it is difficult for students to understand this abstract concept, however, if it applies the multimedia means to specifically demonstrate divisions, sums and taking the limits in calculus in the form of animation with the Montage techniques, it will deepen students' understandings and open up their ideas, achieving the transformation from concreteness to abstract thinking.

\section{Able to Make the Micro World Become Macro}

For those contents and scenes that only need the aid of microscope or local magnifications, it can move the motion process in the microscopic world into the classroom through the use of microscope camera and special lenses, thereby broadening students' horizons to perceive things.

\section{Making Boring Contents Become Interesting}

Due to the audio-visual combination and lifelike colors of the CAI courseware, coupled with the use of a variety of 
special effects, it greatly arouses students' interests in learning.

\section{E. Effectively Improve the Teaching Efficiency}

In colleges and universities, academic terms and the number of credit hours are relatively fixed, whereas knowledge contents and teaching information are rapidly growing, which is a pair of relatively prominent contradiction; the only way to solve this contradiction is to improve the teaching efficiency, which means to improve the learning speed. For teachers, the improvement of the teaching efficiency is in a certain period of time to teach students more knowledge and skills, whereas for students, it is in a certain period of time to learn more skills. Modern teaching means is the most effective way to improve the teaching efficiency. Take the film and television materials for instance, studies on the learning ratio have shown that: people acquire knowledge by visual sensation accounting for $83 \%$, while $11 \%$ by auditory sensation, in which the audiovisual combination has the largest effect; and studies on the concentration ratio have shown that: in learning, the concentration ratio accounts for $81.7 \%$ by the use of visual media, while $54.6 \%$ by the auditory media, which fully explains that students are easy to understand and memorize their acquired knowledge using audio-visual media, with clear perceptions and deep impressions, in which it will significantly improve the learning speed.

\section{PROBLEMS OF MULTIMEDIA EXISTING IN COLLEGE} TEACHING

\section{A. Teachers' Educational Concepts Fail to Keep up with Changes in the Times}

Modern society has entered the information age, and the modern information technology based on computer technologies and network technologies is changing the way in which people work, study and live; at the same time of the modern information technology exercising its influence over the political, economic, and military aspects, it also has a profound impact on education. In the information age, the roles of teachers and students have qualitative changes, and teachers' teaching methods and students' learning methods have also taken place profound changes, however, some teachers have not recognized such changes, who are still continuing to use past educational thoughts and teaching theories, thus affecting the effectiveness of multimedia teaching.

\section{B. Inaccurately Position Teachers' Roles in Multimedia Teaching Methods}

The information age provides the teaching of teachers with advanced teaching means and teaching technology, but also proposes higher requirements for the quality of teachers. To fully play the effectiveness of multimedia teaching, teachers not only needs to have a full understanding of the knowledge hierarchy and content features in the teaching subjects, but also needs to be familiar with characteristics of media as much as possible; moreover, according to the teaching contents and the physiological, psychological, intellectual characteristics of students select the type of media to carry out productions of courseware and organizations of teaching. Teachers are still in the core status in the classroom teaching, playing a vital role in the success or failure of teaching, but some teachers who inaccurately position teachers' roles in multimedia teaching methods consider that the use of multimedia in teaching would result in the reduction of the teacher's role and the relaxation during preparing and delivering lessons, and that it could achieve good teaching effects as long as adopting multimedia in teaching; such inappropriate positioning of teachers' roles also influences the teaching effect of multimedia.

\section{Inaccurately Position Roles of Multimedia in College Teaching}

Multimedia and other modern educational are two technologies with powerful functions, through the use of different media, it can visualize the abstract physical contents, make the microscopic world that human eyes can not see become macro, and demonstrate many interesting physical phenomena and physical processes in classrooms, improving the teaching efficiency. However, everyway multimedia is only an auxiliary facility for teaching, playing a supporting role in the teaching, and the effectiveness of teaching mainly depends on the level of teachers. But some teachers in the past have exaggerated the role of multimedia that it can solve all the problems in teaching; such inappropriate positioning on the role of the media also influences the teaching effect of multimedia.

\section{Inaccurately Position the Relationship between Multimedia Teaching Method and Traditional Teaching Method}

It can know from the previous investigation that multimedia teaching method and traditional teaching method both have their strengths, which in different course contents have their own advantages, but it tends to be in favor that the role of multimedia is larger; it sometimes exaggerates the role of multimedia and other modern teaching means, in which some even thought that the multimedia teaching method is omnipotent to enable to solve all the problems of all subjects in the teaching, on the contrary, very few teachers hold that there is no much usefulness of multimedia in teaching; such two views both are improper, and both will have some negative effects on teachers' instructional designs and classroom teachings, thereby affecting the effectiveness of multimedia teaching.

\section{E. Neglect Applications of Teaching Theories in the Use of Multimedia to Teach}

The teaching process as the process for teachers to teach and students to learn, to fully reflect the leading role of teachers and the subject status of students, when deliver knowledge, it needs to make full use of the theories of education and teaching, and when prepare lessons and give lessons, it needs to consider the existing level of knowledge and intellectual and psychological characteristics of students, in addition it needs to timely review the delivered 
knowledge to strengthen memories, fully mobilizing students' learning initiatives, and using appropriate body language to communicate with students, so as to achieve good teaching effects. However, when some teachers use multimedia to teach, the applications of these teaching theories are neglected, standing in front of a computer for operations, keeping to conventional teachings, lack of exchanges and the communications with students, thus dilute the effectiveness of multimedia teaching.

\section{F. Negative Impacts of Multimedia Itself on Teachings}

Related studies from the perspective of psychology have shown that the more people's attentions are dispersed, the worse the effects of attentions will be. When teachers use the multimedia to teach, operating a computer will attract part of teachers' attentions, and the communications of eyes and gestures with students will be less; for computers currently used in the multimedia classrooms are generally fixed in one place, limiting teachers to play their teaching passions; all these factors will have some negative impacts on the multimedia teaching. Moreover, as in the use of multimedia, the lighting in the classroom is weak, resulting in poor learning states of students, which also affects the teaching effectiveness of multimedia.

The advantages of multimedia in animations, pictures, and videos, etc. are obvious, playing a positive role in demonstrating the microscopic mechanism of materials and creating teaching situations, etc. aspects, and providing an effective platform for the cultivation of innovative talents and the deepening of the quality education, but there are many problems in the multimedia teaching, affecting the roles of multimedia to be normally played, so we have to use psychology, education and other theoretical knowledge to solve these problems, so that multimedia can better serve our educations and teachings.

\section{OPTIMIZE APPLICATION STRATEGIES OF MULTIMEDIA IN COLLEGE TEACHING}

According to our research results and referred materials, it can improve applications of multimedia in college teaching from the following aspects.

\section{A. Improve Introductions of Hardware Facilities}

Hardware facilities are the foundation of CAI, and advanced teaching facilities are the prerequisite to improve the effectiveness of multimedia teaching, which can have a positive impact on teachers' teaching and students' learning, hence, schools should strengthen the construction of hardware facilities and increase investments to introduce a variety of advanced teaching facilities, to provide the material basis for the implementation of multimedia teaching.

\section{B. Increase Construction Efforts of Software Resources, and Strengthen Exchanges and Cooperation among Developers}

Advanced multimedia teaching facilities are the foundation of multimedia teaching, while strong applicability of multimedia courseware is one of the most critical elements in the implementation of multimedia teaching. However, at present, the bottleneck restricting the effectiveness of multimedia teaching is the lack of multimedia teaching resources. Therefore, it needs to take great efforts to carry out the research and development of multimedia courseware.

Increase efforts in the development of teaching resources, increase the investments in the production of multimedia courseware and educational software, and organize specialized personnel to carry out the development and production of courseware; at the same time, carry out trainings for teachers, and launch the compilation and production work on multimedia courseware and electronic teaching materials in an organized and planned way. It also needs to establish appropriate evaluation and incentive mechanisms, protect teachers' intellectual property rights, and increase cooperation and communication efforts among teachers to complement for each other to pool the wisdom of the masses, as well as mobilize more people to suggest ways and means in order to solve the problem of poor courseware resources.

\section{Increase Publicity and Education Efforts to Properly Position Multimedia Teaching Methods}

Though most college teachers use multimedia to teach, and possess certain capacities for the production and development of courseware, yet there is a certain gap for a considerable number of teachers to give lessons with skilled use of multimedia, therefore it should conduct regular trainings for teachers to guide teachers to think deeply of modern educational technology, change their concepts, and truly improve their own levels of theoretical knowledge. Multimedia is only an advanced teaching means, but cannot replace the role of teachers, who are still the organizer and guider in teaching activities and play the core status in the teaching. Teachers are the most critical factor for the success of teaching, and the era puts forward higher requirements for the quality of teachers, so modern college teachers need to establish the concept of lifelong learning, and constantly improve themselves to become the "expert-type" teachers in the information age.

\section{Conduct Various Forms of Trainings for Teachers}

The progress of the times and the development of technologies put forward higher requirements for the quality of teachers. Therefore, schools should actively create opportunities to take different ways to organize teachers to participate in various forms of trainings, in order to improve the level of educational technology.

\section{CONCLUSION}

In this paper, it carries out more in-depth study on the integration of modern educational technology with college curriculums, especially on the application of multimedia technologies in the college teaching and obtains some valuable achievements. There are many issues worthy of study on the integration of modern information technology with college curriculums; in this paper it carries out certain researches from multimedia technologies on issues of 
teaching resources in college curriculums and classrooms, issues of courseware in the production and use processes, and issues of the integration of the traditional teaching method and modern teaching methods, etc., aspects, in which direction many problems are waiting for us to study, explore and solve.

\section{REFERENCES}

[1] Dingxiong Zhu, "Physical Education Outlook". Shanghai: East China Normal University Press, 2006.

[2] Jiqing Wang, “On Information Literacy”. Shanghai: Shanghai Education Press, 2008.
[3] Zhiting Zhu, and Zhixian Zhong, "Modern Educational Technology Promoting the Development of Multiple Intelligences". Shanghai: East China Normal University Press, 2007.

[4] Zengjun Feng, "Contemporary International Educational Development”. Shanghai: East China Normal University Press, 2004.

[5] Zhang Hua, “On Curriculums and Teaching”. Shanghai: Shanghai Education Press, 2008.

[6] Lixin Cong, "Problems in the Curriculum Theory". Beijing: Education Science Press, 2007.

[7] Bingde Li generally editted, “Teaching Theory”. Beijing: People's Education Press, 2005. 